\title{
Avaliação da amônia emitida de camas sobrepostas e piso concretado utilizados na criação de suínos ${ }^{1}$
}

\author{
Robson M. de Paulo ${ }^{2}$, Ilda de F. F. Tinôco ${ }^{3}$, Paulo A. V. de Oliveira ${ }^{4}$, Cecília de F. Souza ${ }^{4}$, Fernando da C. Baêta ${ }^{4}$ \& Paulo R. Cecon ${ }^{4}$
}

\section{RESUMO}

A criação de suínos em camas sobrepostas surgiu como alternativa ao uso excessivo de água utilizada na atividade, mas veio, também, o problema da emissão de gases poluentes, principalmente a amônia. Objetivou-se, com este trabalho, avaliar a quantidade de amônia emitida pelas camas de maravalha, casca de arroz e pelo piso de concreto, comparandoa com os níveis aceitáveis para a produção de suínos criados em camas, entre dezembro de 2002 e abril de 2003, no município de Concórdia, SC; três edificações (12,0 x 10,0 m) foram utilizadas, cada uma com 216 animais (Landrace X Large White) e se avaliou a qualidade do ar quantificando-se a emissão diária de amônia, às dez e quatorze horas; a cama de maravalha, por sua vez, apresentou melhor eficiência na absorção das dejeções em relação à de casca de arroz; entretanto, nela foram encontrados os menores valores de emissão da amônia, enquanto no piso de concreto foram observados os maiores valores para o gás; desta forma, indica-se a cama de maravalha como a mais apropriada para a criação de suínos em condições de verão, para o Sul do Brasil; enfim, a análise estatística lançou mão de um delineamento experimental inteiramente casualizado e 4 repetições por tratamento.

Palavras-chave: maravalha, casca de arroz, gases

\section{Evaluation of the emitted ammonia from deep beddings and concrete floor used in the swine production}

\begin{abstract}
Swine production in deep bedding appeared as an alternative to the excessive use of water in the activity, however the problem of emission of pollutant gases appeared, mainly ammonia. This research aimed at evaluating the amount of ammonia emitted by wood shavings and rice husks deep beds and concrete floor, compared to acceptable levels for swine production in beds, during December 2002 to April 2003, in Concórdia, Santa Catarina State. Three constructions with dimensions of $12.0 \times 10.0 \mathrm{~m}$, divided in 4 boxes with $5.0 \times 6.0 \mathrm{~m}$ were used, each with a total of 216 animals (Landrace X Large White). The evaluation of air quality was based on the quantification of the ammonia emission, daily measurements, at 10:00 a.m. and 2:00 p.m. The wood shaving bed presented better efficiency in the absorption of the wastes compared to the rice husk, which presented the lowest values of ammonia emission. In the concrete floor the highest values were observed for the gas. As such, the wood shaving bed is indicated as the most appropriate for the swine production in summer conditions for the South of Brazil. For the statistical analysis an entirely randomized experimental design, with 4 replicates for each treatment was used.
\end{abstract}

Key words: wood shavings, rice husks, gases

\footnotetext{
1 Parte da Dissertação de Mestrado do primeiro autor

2 UENF, Laboratório de Engenharia Agrícola, Av. Alberto Lamego 2000, Parque Califórnia, CEP 28013-602, Campos dos Goytacazes, RJ. Fone: (22) $2726-1543$. Fax: (22) 2726-1549. E-mail: rmendes@uenf.br

3 DEA/UFV, Av. P.H. Rolfs s/n, CEP 36571-000, Viçosa, MG. Fone: (31) 3899-1884. Fax: (31) 3899-2735. E-mail: ifftinoco@ufv.br

${ }^{4}$ Embrapa Suínos e Aves, CP 21, CEP 89700-000, Concórdia, SC. Fone: (49) 442-8555. Fax: (49) 442-8559, E-mail: paolive@cnpsa.embrapa.br
} 


\section{INTRODUÇÃO}

A amônia é o mais importante gás encontrado em instalações para a criação de suínos, podendo ocorrer em níveis bastante altos, além de ser um irritante ao sistema respiratório; pode, também, afetar a saúde dos animais e dos trabalhadores que atuam na atividade.

Segundo Heber et al. (2002) a amônia pode causar pneumonias e diminuição da taxa de crescimento nos animais, visto que o gás tem odor distinto e é detectado pelo homem em concentração de 5 ppm. A concentração máxima recomendada pelo NIOSH (1996) é da ordem de 25 ppm; por outro lado, pesquisadores europeus sugerem um limite da ordem de 10 ppm.

Oliveira (2000) em experimento realizado no Laboratório de Bioclimatologia do INRA-França e comparando o sistema de cama sobreposta com o sistema de piso ripado, constatou que as concentrações médias de amônia observadas foram significativamente diferentes, sendo que o sistema de cama apresentou as menores concentrações.

A cama absorve o componente líquido do resíduo, separando-o dos sólidos, reduzindo a velocidade do processo de decomposição, que produz combinações como amônia e sulfito de hidrogênio, sendo assim mínimo o odor nessas instalações (Chapin et al., 1998).

Paulo (2003) avaliando a temperatura de camas sobrepostas e piso de concreto, concluiu que no período da manhã (9 h), a temperatura da cama de maravalha foi maior que a cama com casca de arroz. Entre a cama de casca de arroz e o piso de concreto, não houve diferença de temperatura. A alta produção de calor gerada nas camas tende a influenciar no comportamento e desempenho dos animais. As temperaturas elevadas indicam que a atividade bacteriana produz calor suficiente para evaporar a água da cama, favorecendo a emissão de gases produzidos nas camas, pelos animais. A cama gera grandes quantidades de calor por meio da degradação da matéria orgânica.

Segundo Paulo (2003) deve-se considerar que o uso de camas sobrepostas na suinocultura proporciona economia significativa de água utilizada nos processos produtivos e evita o lançamento das águas residuárias nos cursos d'água.

Dartora et al. (1998) concluíram que boa parte dos sistemas de criação de suínos existentes no Brasil resulta em elevada produção de dejetos líquidos, gerando problemas de manejo, armazenamento, distribuição e poluição ambiental. Ainda de acordo com eles, somente no Estado de Santa Catarina $80 \%$ das fontes de água e a maioria dos rios e riachos do oeste e meio oeste estão contaminados. Levantamentos realizados em zonas rurais das regiões produtoras de suínos de Santa Catarina, revelam que $85 \%$ das fontes de água estão contaminados por coliformes fecais, oriundos do lançamento direto de esterco de suínos em cursos ou mananciais d’água (Lohmann et al., 1999).

O uso de camas sobrepostas sobre o piso como alternativa ao tradicional de piso de concreto, vem-se tornando uma prática constante na criação de suínos nas fases de crescimento e terminação, pois evita a utilização de lagoas para tratamento de dejetos.
Com base no ganho de peso, consumo de ração e consumo de água, Paulo (2003) concluiu que o desempenho zootécnico não foi influenciado pelas camas de maravalha, casca de arroz nem pelo piso de concreto; entretanto, os animais mantidos no piso de concreto apresentaram resultados ligeiramente melhores que os alojados nas camas sobrepostas.

O desempenho zootécnico dos animais criados no sistema de camas sobrepostas, é similar ao daqueles criados no piso convencional, além de melhor bem-estar, sustentabilidade ambiental e menor custo inicial (Hill, 2000).

Tendo como base os resultados do índice de temperatura de globo negro e umidade (ITGU), carga térmica de radiação (CTR) e umidade relativa do ar (UR), Paulo (2003) observou discreta vantagem para o piso de concreto. Dentre as camas, a casca de arroz se mostrou mais eficiente; a umidade relativa do ar esteve sempre acima do valor considerado limite para suínos em crescimento e terminação, que é de $75 \%$.

Objetivou-se, com o presente trabalho, avaliar se a quantidade de amônia $\left(\mathrm{NH}_{3}\right)$ emitida pelas camas sobrepostas compostas de maravalha e de casca de arroz e pelo piso de concreto, utilizadas na criação de suínos em crescimento e terminação, para as condições de verão do Sul do Brasil, é prejudicial aos animais e ao homem, de acordo com níveis tolerados internacionalmente.

\section{MATERIAL E MÉTODOS}

O experimento foi realizado no Centro Nacional de Pesquisa de Suínos e Aves da EMBRAPA (EMBRAPA/CNPSA), localizado no Distrito de Tamanduá, na cidade de Concórdia, Estado de Santa Catarina, situada a 584,0 m de altitude, com Latitude de $27^{\circ} 18^{\prime} \mathrm{S}$ e Longitude de $51^{\circ} 59^{\prime} \mathrm{O}$, no período de dezembro de 2002 a abril de 2003. As instalações se compunham de três galpões, medindo 12,0 x 10,0 m e pé direito de $3,25 \mathrm{~m}$; cada galpão foi dividido em quatro baias com dimensões de 5,0 x 6,0 m; cobertura de telhas de fibrocimento com lanternim. Os fechamentos laterais, com 1,0 m de altura, eram constituídos de placas vazadas de concreto e/ou grades de ferro A distância entre as instalações era de 10,0 m. Na primeira instalação utilizou cama de maravalha; na segunda, casca de arroz e, na terceira, piso de concreto. Foram utilizados 216 animais das raças Landrace e Large White (machos castrados e fêmeas), com peso médio inicial de $25 \mathrm{~kg}$ e idade média de 63 dias, compreendendo as fases de crescimento e terminação. Os animais receberam, durante o período experimental (120 dias) a mesma dieta.

Para efeito de estudo da emissão de amônia dividiu-se o período experimental em três fases, que compreendiam os intervalos de pesagem: 1) 25-50; 2) 50-75 e 3) 75-135 kg. Os animais foram alojados em grupo de 72 por instalação (18 animais por baia); as baias possuíam área útil de $21,0 \mathrm{~m}^{2}$ (4,2 x 5,0 m) e profundidade de 0,50 m (instalações com camas); as baias foram equipadas com um bebedouro e um comedouro, recebendo água e ração à vontade. Para quantificar a emissão de amônia foram feitas medições de concentração instantânea (ppm) a 0,25 m do piso, correspondente 
ao nível médio do dorso dos animais (focinho do suíno).

As medições foram realizadas em dois horários (10 e 14 h), em períodos diários, sendo uma leitura por baia na área considerada crítica (local das dejeções), durante o período experimental. Para a coleta de dados utilizou-se um detector eletroquímico portátil de leitura direta da marca Crowcon com faixa de leitura de 0-50 ppm, temperatura de operação de -20 a $50{ }^{\circ} \mathrm{C}$ e umidade de 0 a $95 \%$. Os dados foram analisados por meio de regressão, através do programa SAEG 5.0.

\section{RESULTADOS E DISCUSSÃO}

Por meio das médias diárias realizadas nos dois tratamentos estudados (cama de maravalha e cama de casca de arroz), apresentadas na Tabela 1 , observa-se que não houve diferença significativa $(\mathrm{P}<0,05)$ quando comparados ao tratamento convencional com piso de concreto.

Tabela 1. Médias* dos valores de emissão de amônia $\left(\mathrm{NH}_{3}\right)$, em partes por milhão (ppm), medidas nas camas de maravalha e casca de arroz comparadas com o piso de concreto

\begin{tabular}{cc}
\hline Tratamento & Médias \\
Maravalha & $3,30 \mathrm{~A}$ \\
Casca de arroz & $2,98 \mathrm{~A}$ \\
Piso de concreto & $5,20 \mathrm{~A}$ \\
\hline
\end{tabular}

* As médias seguidas de pelo menos uma mesma letra não diferem entre si pelo Teste de Tukey $(P<0,05)$

Os picos foram observados de 16, 15 e 22 ppm para as camas de maravalha, arroz e piso de concreto, respectivamente; os resultados encontrados nas camas permaneceram abaixo daqueles constatados por Oliveira (2000) que trabalhou com suínos mantidos em piso ripado, ou seja, de $15,20 \pm 6,40 \mathrm{ppm}$. Os valores médios para o piso de concreto estão de acordo com os resultados obtidos por Oliveira (2000), ou seja, 9,20 \pm 4,20 ppm para os valores de emissão de amônia $\left(\mathrm{NH}_{3}\right)$.

No comparativo entre as três fases de observação, ocorreu diferenciação na emissão de amônia, por parte das camas. Nas fases $1(63$ - 98) e $2(98$ - 126d) não se constatou diferença significativa entre os dois tratamentos, porém os valores para a cama de maravalha foram ligeiramente superiores, talvez pelo fato do material absorver mais as dejeções que a cama de casca de arroz, além da constante movimentação pelos animais; entretanto, esses valores para a emissão do gás não comprometem a saúde dos animais; na terceira fase se observaram os maiores valores médios quando comparados com as duas primeiras (Tabela 2). Possivelmente em razão desta fase compreender um período maior de observação (57 dias, contra 35 e 28 para as fases 1 e 2, respectivamente) outra explicação pode ser dada com base no peso maior dos animais e, por conseqüência, maior volume de dejeções produzido por animal nas camas, uma vez que houve aumento no consumo de água e alimento, diferente do que ocorre no inverno, quando temperaturas menores não favorecem tanto o consumo de água quanto no verão.
Tabela 2. Médias* dos valores de emissão de amônia $\left(\mathrm{NH}_{3}\right)$, em partes por milhão (ppm), medidas em cada fase do experimento, para os tratamentos

\begin{tabular}{lc}
\hline Fase & Médias \\
1) $63-98 \mathrm{~d}$ & $2,20 \mathrm{~A}$ \\
2) $98-126 \mathrm{~d}$ & $2,06 \mathrm{~A}$ \\
3) $126-183 \mathrm{~d}$ & $5,15 \mathrm{~B}$ \\
\hline
\end{tabular}
Tukey $(P<0,05)$

Maiores valores para emissão de amônia em cama de maravalha foram observados por Cordeiro (2003), que trabalhando com suínos em crescimento e terminação em condições de inverno, observou diferença significativa na emissão de amônia, sendo os maiores valores para as camas de maravalha e casca de arroz, quando comparados com o piso de concreto; o autor concluiu que os valores ficaram abaixo de $20 \mathrm{ppm}$.

Confirmando os valores mais altos para as condições de inverno, Sampaio et al. (2006) concluíram que as mais altas concentrações de amônia foram observadas no inverno e mais especificamente nos horários da tarde, correspondendo aos horários de maior temperatura do ar.

Andersson (1996) observou maiores valores para emissão de amônia em cama com palha quando comparado com outros tratamentos semelhantes e em tempos diferentes.

É importante observar que, em média, os valores de concentração de amônia $\left(\mathrm{NH}_{3}\right)$ no tratamento piso de concreto foram $37 \%$ maiores quando comparados com o tratamento cama de maravalha e $44 \%$ quando a comparação se refere ao tratamento cama de casca de arroz. Pode-se observar, na Figura 1, os valores encontrados nas camas e no piso convencional comparados àquele considerado padrão.

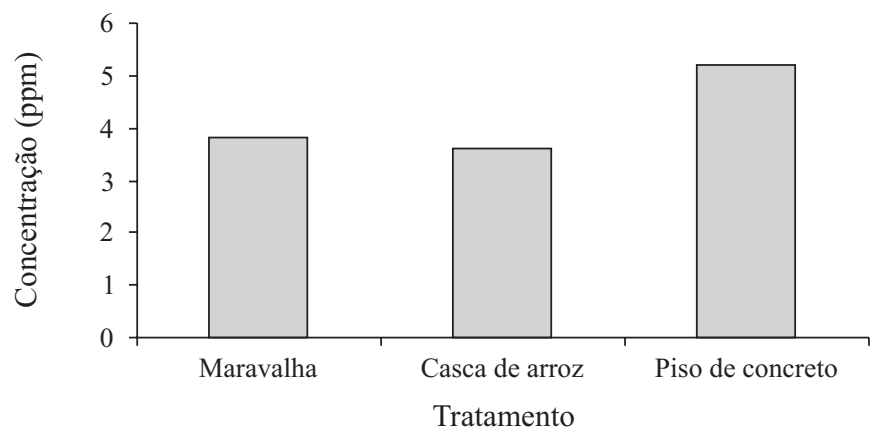

Figura 1. Comparação dos valores de amônia emitidos pelas camas de maravalha e casca de arroz com o piso de concreto e o mínimo tolerado pelos suínos (padrão)

Os valores da concentração de amônia obtidos nas camas de maravalha e de casca de arroz estão abaixo daquele recomendado por pesquisadores da área, que é da ordem de 10 ppm; o que também pode ter influenciado diretamente os resultados, é a incidência da ventilação nas instalações (abertas) durante todo o período de criação, o que não ocorre em países da Europa nem nos Estados Unidos, onde as instalações são completamente fechadas. A insolação direta sobre as camas também pode ter efeito benéfico pois não permitia, em algumas partes, a umidade das dejeções. 
Por ser rugoso, o piso de concreto usado no comparativo pode ter influenciado nos maiores valores médios de concentração de amônia; a parte ripada com o canal condutor, situado sob a instalação, pode ser outra explicação para esses valores. Outra explicação reside no fato de os animais de maior porte possuírem maior capacidade de revolver as camas e, portanto, aeração mais eficiente, com isso as perdas atmosféricas seriam mais pronunciadas (Higarashi et al., 2008).

De maneira geral, os níveis médios de amônia encontrados nas instalações em condições de verão não tendem a causar conseqüências mais graves aos animais, por estarem abaixo dos níveis críticos.

Os valores observados estão de acordo com os valores estipulados por organismos internacionais, a exemplo da NIOSH (1996), que recomenda que a concentração máxima do gás não seja superior a 25 ppm, bem mais elevada que aquela sugerida por pesquisadores da Europa, que é da ordem de 10 ppm (Heber et al., 2002); geralmente, os níveis da amônia são mais elevados no verão; esta elevação nos níveis de amônia pode estar associada ao fato dos animais ingerirem uma quantidade maior de água e a necessidade de constante alimentação, quadro que gera, também, maior produção de dejetos sólidos e líquidos e, por conseqüência, maior produção de gases nas instalações. Segundo Harmon \& Xin (1995) apud Santos (2001), o nível máximo tolerado para a amônia $\left(\mathrm{NH}_{3}\right)$ nas instalações para suínos, é de 10 ppm; o gás pode ser facilmente detectado por meio do odor, na concentração de 5 ppm ou mais; a partir de 50 ppm, passa a afetar o crescimento e a saúde dos animais e, em sendo mais leve que o ar, tende a concentrar-se junto à cobertura das instalações; sua concentração depende muito da higiene local e da eficiência da ventilação.

Em algumas ocasiões os valores instantâneos superaram os limites considerados críticos por pesquisadores e organismos internacionais devido, sem dúvida, à agitação das camas pelos animais, comportamento considerado normal.

\section{CONCLUSÕES}

1. A maravalha apresentou melhor eficiência na absorção das dejeções, sendo mais indicada, portanto, para compor as camas para a suinocultura.

2. Tanto a cama de maravalha quanto a de casca de arroz apresentaram valores para a emissão de amônia abaixo dos limites estabelecidos por pesquisadores e organismos internacionais.

3. A utilização de camas sobrepostas na criação de suínos possibilita economia de água, uma vez que não há necessidade de se lavar constantemente as baias para limpeza das dejeções produzidas pelos animais.

4. Ao final da criação, a cama fornece material orgânico pronto para utilização nas plantações, em decorrência do manejo do esterco seco e do acúmulo dos nutrientes $\mathrm{N}$, P e K.

\section{AGRADECIMENTOS}

Os autores expressam seus agradecimentos ao apoio concedido pelo CNPq, CAPES, FAPEMIG e EMBRAPA Suinos e Aves. Agradecimento especial à professora Dra. Ilda Tinôco (DEA/UFV) pela dedicação e incentivo.

\section{LITERATURA CITADA}

Andersson, M. Performance of bedding materials in affecting ammonia emissions from pig manure. Journal of Agricultural Engineering Research, v.65, n.3, p.213-222, 1996.

Chapin, A.; Boulind, C.; Moore, A. Controlling odor and gaseous emission problems from industrial swine facilities - Recent laws and new ideas. Yale: Environmental Protection Clinic, 1998. 81p.

Cordeiro, M. B. Avaliação de sistema de camas sobrepostas quanto ao conforto térmico e ambiental e ao desempenho zootécnico para suínos nas fases de crescimento e terminação. Viçosa: UFV, 2003. 63p. Dissertação Mestrado

Dartora, V.; Perdomo, C. C.; Tumelero, I. L. Manejo de dejetos de suínos. Boletim Informativo Pesquisa BIPERS, Embrapa Suínos e Aves/Extensão-EMATER-RS, n.11, ano 7, 1998.

Heber, A.; Jones, D.; Sutton, A. Indoor air quality: Controlling ammonia gas in swine buildings. Purdue University Cooperative: Extension Service. http://cdc.gov/niosh/nasd/docs4/ in98003.html. 20 Ago. 2002.

Higarashi, M. M.; Coldebella, A.; Oliveira, P. A. V.; Kunz, A.; Mattei, R. M.; Silva, V. S.; Amaral, A. L. Concentração de macronutrientes e metais pesados em maravalha de unidade de suínos em cama sobreposta. Engenharia Agrícola e Ambiental, v.12, n.3, p.311-317, 2008.

Hill, J. D. Deep bed swine finishing. In: Seminário Internacional de Suinocultura, 5, São Paulo. Anais... Concórdia: Embrapa Suínos e Aves, 2000. p.83-88.

Lohmann, O.; Silva, R. F.; Fontoura, T. B.; Silva, D. M.; Jaques, R. J. S.; Fries, M. R.; Aita, C. Determinação de microrganismos fecais em solo, sob campo nativo, submetidos a aplicações periódicas de esterco suíno. In: Congresso Brasileiro de Ciência do Solo, 27, 1999, Brasília. Anais... Brasília: Embrapa Cerrado, 1999. CD Rom.

NIOSH - National Institute of Occupational Safety and Health. Safety in swine production systems. North Carolina: Cooperative Extension Service Publications. n. PIH - 104, 1996.

Oliveira, P. A. V. Produção de suínos em sistema “deep bedding”: experiência brasileira. In: Seminário Internacional de Suinocultura, 5, 2000, São Paulo. Anais... Concórdia: EMBRAPA/CNPSA, 2000. p.101-107.

Paulo, R. M. Uso de camas sobrepostas durante as fases de crescimento e terminação de suínos em condições de verão. Viçosa: UFV, 2003. 65p. Dissertação Mestrado

Sampaio, C. A. P.; Nääs, I. A.; Salgado, D. D. Amônia, gás sulfídrico, metano e monóxido de carbono na produção de suínos. Ciências Agroveterinárias, v.5, n.2, p.156 -164, 2006.

Santos, M. A. A. Efeitos da ventilação natural em instalações de suínos em crescimento e terminação. Campinas: UNICAMP, 2001. 90p. Tese Doutorado 